\title{
Blockade of the GLT-I Transporter in the Central Nucleus of the Amygdala Induces both Anxiety and Depressive-Like Symptoms
}

\author{
Catherine S John', Elizabeth I Sypek', William A Carlezon', Bruce M Cohen', Dost Öngür' and \\ Anita J Bechtholt*,2,3 \\ 'Department of Psychiatry, Harvard Medical School_McLean Hospital, Belmont, MA, USA; ${ }^{2}$ National Institute on Alcohol Abuse and Alcoholism, \\ NIH, Bethesda, MD, USA
}

\begin{abstract}
Depression has been associated with abnormalities in glutamatergic neurotransmission and decreased astrocyte number in limbic areas. We previously demonstrated that global and prefrontal cortical blockade of the astrocytic glutamate transporter (GLT-I) induces anhedonia and c-Fos expression in areas that regulate anxiety, including the central amygdala (CEA). Given the role of the amygdala in anxiety and the high degree of comorbidity between anxiety and depression, we hypothesized that GLT-I blockade in the CEA would induce symptoms of anhedonia and anxiety in rats. We microinjected the GLT-I inhibitor, dihydrokainic acid (DHK), into the CEA and examined effects on intracranial self-stimulation (ICSS) as an index of hedonic state, and on behavior in two anxiety paradigms, elevated plus maze (EPM) and fear conditioning. At lower doses, intra-CEA DHK produced modest increases in ICSS responding (TO). Higher doses resulted in complete cessation of responding for $15 \mathrm{~min}$, suggesting an anhedonic or depressive-like effect. Intra-CEA DHK also increased anxiety-like behavior such that percent time in the open arms and total entries were decreased in the EPM and acquisition of freezing behavior to the tone was increased in a fear-conditioning paradigm. These effects did not appear to be explained by non-specific changes in activity, because effects on fear conditioning were assessed in a drug-free state, and a separate activity test showed no significant effects of intra-CEA DHK on locomotion. Taken together, these studies suggest that blockade of GLT-I in the CEA is sufficient to induce both anhedonia and anxiety and therefore that a lack of glutamate uptake resulting from glial deficits may contribute to the comorbidity of depression and anxiety.

Neuropsychopharmacology (20I5) 40, 1700-1708; doi:I0.1038/npp.20I5.16; published online I8 February 20I5
\end{abstract}

\section{INTRODUCTION}

Generalized anxiety disorder (GAD) is one of the most common psychiatric illnesses diagnosed in combination with major depressive disorder (MDD) (Sunderland et al, 2010). This co-occurrence has led to theories suggesting that similar etiologies and pathophysiological abnormalities underlie anxiety and mood disorders (for review see Mineka et al, 1998). Cases of MDD without concomitant anxiety are more rare than cases of comorbid MDD and GAD with most populations consistently showing rates of comorbidity

*Correspondence: Dr AJ Bechtholt, Division of Treatment and Recovery Research, National Institute on Alcohol Abuse and Alcoholism, National Institutes of Health, 5635 Fishers Lane, Room 2046, Bethesda, MD 20892-9304, USA, Tel: +I 30I 4439334, Fax: + I 30 I 443 8774, E-mail: Anita.bechtholt@gmail.com

${ }^{3} \mathrm{Dr}$ Bechtholt contributed to this article as an employee of McLean Hospital. The views expressed are her own and do not necessarily represent the views of the National Institutes of Health or the United States Government.

Received 21 August 2014; revised 15 December 2014; accepted 5 January 20 I5; accepted article preview online 14 January 2015 between 50 and 70\% (Brawman-Mintzer et al, 1993; Kessler et al, 1999; King-Kallimanis et al, 2009). Common genetic polymorphisms have been associated with higher risk for developing anxiety or depression (Jardine et al, 1984), suggesting that such high rates of comorbid anxiety with MDD may be a prodromal or residual aspect of depression itself (Kessler et al, 2008; Sunderland et al, 2010). Individuals who experience comorbid GAD and MDD have greater severity of illness including increased suicidal ideation and higher levels of pathological worry (Zimmerman and Chelminski, 2003). Furthermore, depression with comorbid anxiety is not well treated by standard treatments, creating a population of individuals who are categorized as treatment resistant (Newman et al, 2010; Gadermann et al, 2012). High rates of comorbidity, symptom overlap (Brown et al, 1995; Zbozinek et al, 2012), and common underlying brain abnormalities between anxiety and depressive disorders have lead to novel insights into networks that may regulate both anhedonia and anxiogenesis. In particular, the amygdala has been implicated in both disorders, and some findings suggest that cellular and molecular changes in cortical networks 
that influence anxiety, including the prefrontal cortex and the amygdala, are impaired in MDD (Drevets, 2000; Gosselin et al, 2009).

Depression is associated with molecular and volumetric changes in regions that are known to regulate both hedonic and anxiety states. The amygdala is important for the interpretation of emotional meaning, and it has been reported that patients with depression have impaired function during emotional tasks involving the amygdala (Sheline et al, 1998) and that patients with mood disorders consistently display volumetric reductions in the amygdala with imaging studies (Sheline et al, 1998; Mervaala et al, 2000; Blumberg et al, 2003; Blumberg et al, 2005; Chang et al, 2005; Rosso et al, 2007). These changes have been attributed to a decrease in glial cells, with both astrocytes and oligodendrocytes being reduced in number without a concomitant loss of neurons (Bowley et al, 2002; Gosselin et al, 2009; Altshuler et al, 2010). Treatment-resistant depression is also associated with increased metabolic activity in the amygdala (Ketter et al, 2001) which is positively correlated with negative affect (Abercrombie et al, 1998), suggesting that abnormally high amygdala activity may contribute to symptom severity. Increased glutamate levels in both the amygdala and prefrontal cortex have also been associated with MDD (Sanacora et al, 2004; Hashimoto et al, 2007), suggesting that increases in amygdala activity could be due to higher glutamate levels. Similarly, downregulation in the high-affinity astrocytic glutamate transporters SLC1A2 (EAAT2) and SLC1A3 (EAAT1) has been identified in the anterior cingulate of postmortem human tissue (Choudary et al, 2005); abnormalities that may contribute to elevated glutamate levels in the amygdala because of dense connectivity between the two regions (Carmichael and Price, 1995; Ongur and Price, 2000). These findings suggest compromised metabolism of glutamate in the depressed brain, and as astrocytes account for at least 90 percent of glutamate uptake (Chaudhry et al, 1995; Lehre et al, 1995; Haugeto et al, 1996; Lehre and Danbolt, 1998), deficits in glial cells may drive the increased cortical activation reported in depression. These findings suggest that heightened activity in the amygdala may contribute to increased anxiety in depressed patients.

Preclinical studies have provided some insight into how elevated glutamate levels in specific brain regions may account for anhedonia, however, it is not yet clear whether elevated glutamate levels in these regions can also induce anxiety-like behavior. We have previously demonstrated that central infusion of the GLT-1 inhibitor dihydrokainic acid (DHK) produces depressive-like symptoms in rats and induces c-Fos expression in a number of limbic regions, including the central amygdala (CEA) (Bechtholt-Gompf et al, 2010). Additional work has further shown that pharmacological blockade of glutamate uptake in the amygdala (Lee et al, 2007) is sufficient to induce depressive-like social behavior in rats. As anxiety is highly comorbid with depression and metabolic activity of the amygdala is increased in both disorders, the present report investigates the effects of blocking astrocytic glutamate uptake in the CEA using DHK in paradigms that quantify both anhedonic- and anxiogenic-like behavior.

The present work is designed to model one aspect of cell loss in the central nucleus of the amygdala (CEA) in rats and therefore, to determine whether changes in glial glutamate uptake could induce concomitant anxiety- and depressive-like symptoms. We have previously reported that ICV or intra-PFC DHK is capable of increasing intracranial selfstimulation (ICSS) thresholds and latency to begin drinking sucrose, suggesting that both central and region-specific increases in glutamate can induce anhedonic-like symptoms in rats (Bechtholt-Gompf et al, 2010; John et al, 2012). Here, we used ICSS as a measure of motivation and anhedonia (Carlezon and Chartoff, 2007) to determine whether intraCEA DHK is sufficient to replicate the anhedonic-like effects we observed previously with ICV infusion. In addition, because the CEA has been heavily implicated in anxiety and fear responses, we hypothesized that intra-CEA DHK infusion would induce or exacerbate anxiety-like behavior which we assessed using the elevated plus maze (EPM) and a fearconditioning paradigm. As increases in glutamate can have effects on activity, we augmented these findings with a locomotor test to determine whether gross changes in movement occurred that could account for the observed changes. Taken together, these findings suggested that increased glutamate in the CEA could contribute to the high comorbidity between depressive and anxiety disorders.

\section{MATERIALS AND METHODS}

\section{Animals}

Fifty-six male Sprague-Dawley rats (Charles River Laboratories Inc.) weighing $300-350 \mathrm{~g}$ at the time of surgery were used in these studies. After surgery, the rats were housed singly and maintained on a 12-h light-dark cycle with food and water available ad libitum. Each experiment used naive cohorts of rats. Procedures were conducted between 0900 and $1800 \mathrm{~h}$ with the approval of the McLean Hospital Institutional Animal Care and Use Committee and within the guidelines of The National Research Council's Guide for Care and Use of Laboratory Animals.

\section{Drugs}

DHK (Tocris Bioscience, Ellisville, MO) blocks the uptake of glutamate into astrocytes (Arriza et al, 1994; Anderson and Swanson, 2000), resulting in increased extrasynaptic glutamate. This effect has been shown both ex vivo (Robinson et al, 1991) and in vivo (Fallgren and Paulsen, 1996). DHK does not bind to AMPA/kainite or other glutamate receptors with significant affinity (Johnston et al, 1979), indicating selectivity for GLT-1. Doses of DHK were derived from preliminary studies and previously published behavioral data (Lee et al, 2007; Bechtholt-Gompf et al, 2010; John et al, 2012). DHK was dissolved in phosphate-buffered saline ( $\mathrm{pH} 7.4$ ) as previously reported (Lee et al, 2007). In all experiments, DHK $(0.0,1.563,3.125,6.25,9.375$, or $12.5 \mathrm{nmol}$ in $1 \mu \mathrm{l} ; 0.5 \mu \mathrm{l}$ per side) was delivered at a rate of $0.25 \mu \mathrm{l} / \mathrm{min}$ and injectors were left in place for $1 \mathrm{~min}$ after the infusion to allow for adequate diffusion.

\section{Surgery}

Rats were implanted with monopolar stainless steel stimulating electrodes $(0.25 \mathrm{~mm}$ diameter $)$ aimed at the 
medial forebrain bundle (10 degree angle; from bregma $4.2 \mathrm{~mm}$ posterior, $+1.7 \mathrm{~mm}$ lateral, $7.9 \mathrm{~mm}$ ventral from the dura) and/or bilateral cannulae (23 ga.) aimed at the CEA (with ICSS electrode for long-term studies: 10 degree angle; from bregma $1.6 \mathrm{~mm}$ posterior, $+/-4.4 \mathrm{~mm}$ lateral, $5.7 \mathrm{~mm}$ ventral from dura; without ICSS electrode for shortterm studies: from bregma $2.6 \mathrm{~mm}$ posterior, $4.4 \mathrm{~mm}$ lateral, $5.6 \mathrm{~mm}$ ventral from the dura with an additional $1.5 \mathrm{~mm}$ injector projection) (Paxinos and Watson, 2007). Coordinates are different in ICSS electrode-implanted rats because of spatial limitations and because the long training time required for ICSS and the consequent rat skull growth requires different coordinates for placement in the same brain region relative to cannulae implanted days prior to histological verification. Rats were anesthetized with Nembutal $(65 \mathrm{mg} / \mathrm{kg}$, IP) and small burr holes were made in the skull through which an electrode and/or guide cannula was lowered to the specified depth under stereotaxic guidance. The electrodes and guide cannulae were fastened to the skull using stainless steel screws and dental acrylic. The rats were allowed 5 days undisturbed to recover prior to the start of experimentation.

\section{Intracranial Self-Stimulation}

Because ICSS is sensitive to manipulations that induce anhedonia (Carlezon and Chartoff, 2007), we used this behavior to assess changes in hedonic state after DHK treatment. The rats were trained on a fixed-ratio-one schedule of reinforcement to obtain brain stimulation as previously described (Carlezon and Chartoff, 2007; Bechtholt-Gompf et al, 2010; John et al, 2012). Briefly, rats were trained to lever press for a 0.5 -s pulse train. The stimulation current $(100-300 \mu \mathrm{A})$ was adjusted for each animal to the lowest level that sustained responding at a rate greater than 1 lever press/s. After stable responding was reached, the rats were trained to lever press for a series of 15 descending frequencies $(158-32 \mathrm{~Hz}$ at descending $0.05 \log 10$ units), which was termed a 'pass' after completion of all 15 descending frequencies. Daily training sessions were conducted 5 days per week and consisted of four consecutive passes, which typically spanned 6-8 weeks. To characterize the relationship between response strength and reward magnitude, the least-squares best fit line was plotted across the frequencies that maintained responding at $20,30,40,50$, and $60 \%$ of the maximum response. From this function, the ICSS threshold was defined as the frequency at which the function intersects with the $x$-axis (theta-0; T0) (Miliaressis et al, 1986), which represents the point at which the stimulation becomes rewarding. The maximum rate of responding (Max Rate) was calculated in parallel to assess performance. Drug test sessions began the day after mean ICSS thresholds varied by $< \pm 10 \%$ across five training sessions. On test days, rats were allowed to press through three baseline passes, infused bilaterally intra-CEA with one of six doses of DHK (total bilateral infusion: 0.0, 1.563, $3.125,6.25,9.375$, or $12.5 \mathrm{nmol}$ in $1 \mu \mathrm{l} ; 0.5 \mu \mathrm{l}$ per side) and then subjected to three additional passes. Each animal was administered each dose in increasing order on separate test days with treatment days interspersed with baseline recovery days.

\section{Elevated Plus Maze}

The EPM is a test that is commonly used in rodents to assess unconditioned fear (Montgomery, 1955) and was conducted to assess the potential anxiogenic properties of intra-CEA DHK using standard procedures (Walf and Frye, 2007). Rats ( $n=16 ; 8$ per group) were tested on a black plastic maze (Hamilton-Kinder, San Diego, CA) that was $110 \times 110 \times 85 \mathrm{~cm}$ (length $\times$ width $\times$ height). Each arm of the maze was $10 \times 50 \mathrm{~cm}$ (width $\times$ length) and the intersection of the arms was $10 \times 10 \mathrm{~cm}$. The closed arms were $40 \mathrm{~cm}$ high. Rats were habituated to the experimenter and microinfusion procedures using gentle handling and headcap adjustment for 5 days prior to testing. On test day, rats were transferred to a holding room adjacent to the EPM testing room and were allowed to acclimate to the environment for at least $1 \mathrm{~h}$. Rats were then transferred into the EPM testing room, which was illuminated by a dim red light $(25 \mathrm{~W})$, and were allowed to acclimate to the room for $5 \mathrm{~min}$ prior to testing. Separate groups of rats received bilateral microinfusions of either vehicle or DHK $(12.5 \mathrm{nmol}$ in $1 \mu \mathrm{l} ; 0.5 \mu \mathrm{l}$ per side) immediately before being placed in the center of the EPM. After completion of a $5 \mathrm{~min}$ trial, rats were returned to their home cage and the EPM was cleaned using $70 \%$ EtOH wipes. Behavior was recorded and automatically tabulated using an overhead camera and Ethovision software (Noldus, Leesburg, VA).

\section{Fear Conditioning}

A separate group of rats $(n=16 ; 8$ per group $)$ were tested in the single trail fear-conditioning paradigm to further assess the effects of intra-CEA DHK on the acquisition of conditioned freezing behavior. Testing of rats was conducted in four identical startle cages consisting of $19 \times 9 \times 14 \mathrm{~cm}$ Plexiglas and steel-rod floor bars attached to a load-cell platform. Both the startle cages and platform were contained within a $69 \times 36 \times 42 \mathrm{~cm}$ ventilated soundattenuating isolation box with the inside temperature monitored and maintained at $\sim 20^{\circ} \mathrm{C}$ (Med Associates, Georgia, VT). Constant wide-band background noise $(60 \mathrm{~dB} ; 10-20 \mathrm{kHz})$ was generated by an audio stimulator (Med Associates) and delivered through speakers located $7 \mathrm{~cm}$ behind the startle cage. The calibration, presentation, and sequencing of all stimuli were under the control of the personal computer using specially designed software (Med Associates). After 7 days of surgical recovery, half of the animals were infused with vehicle and the other half with DHK (12.5 nmol). Immediately following infusion, rats were placed into the conditioning chamber for $2 \mathrm{~min}$ before the onset of the conditioned stimulus (CS). The CS was a tone $(5 \mathrm{kHz}, 75 \mathrm{~dB})$ that lasted for $30 \mathrm{~s}$. The last $2 \mathrm{~s}$ of the CS were paired with a continuous foot shock $(0.6 \mathrm{~mA}$, the unconditioned stimulus). After additional $30 \mathrm{~s}$ in the chamber, the rat was returned to his home cage. Rats were tested at $24 \mathrm{~h}$ after training. For the test, rats were returned to the fearconditioning chambers and 2 min later, were exposed to the tone CS for $60 \mathrm{~s}$. Behavior during exposure to both the context and tone CS was videotaped and freezing scores rated by a blinded observer and calculated as the percentage of the total duration that the rat remained immobile (frozen) other than breathing. 


\section{Activity Testing}

As higher doses of intra-CEA DHK resulted in complete cessation of ICSS responding, reductions in the total number of entries in the EPM, and increased freezing in the fear-conditioning paradigm, locomotor activity was assessed to determine whether these results could be due to impaired locomotion or generalized immobility. Rats ( $n=16 ; 8$ per group) were bilaterally infused with either intra-CEA vehicle or the highest dose of DHK (12.5 nmol in $1 \mu \mathrm{l} ; 0.5 \mu \mathrm{l}$ per side) immediately before being placed in a lit activity chamber for $30 \mathrm{~min}$. Activity was monitored in automated chambers $(43 \mathrm{~L} \times 43 \mathrm{~W} \times 31 \mathrm{H} \mathrm{cm}$; Med Associates, St Albans, VT). Photobeam breaks during 5-min intervals were used to automatically calculate the distance traveled $(\mathrm{cm})$ and velocity $(\mathrm{cm} / \mathrm{s})$ during each interval.

\section{Histological Verification}

After the last test session, rats were anesthetized with sodium pentobarbital $(130 \mathrm{mg} / \mathrm{kg}$ IP) and transcardially perfused with $0.9 \% \mathrm{NaCl}$ followed by $4 \%$ paraformaldehyde in isotonic sodium phosphate-buffered saline. Brains were then removed, post-fixed for $24 \mathrm{~h}$, and then cryoprotected with $30 \%$ sucrose. Frozen $40-\mu \mathrm{m}$ coronal sections were cut through the site of the microinjectors using a microtome and collected in phosphate-buffered saline with $0.05 \%$ sodium azide. Sections were then mounted onto slides and stained with cresyl violet. Rats given microinjections outside of the CEA were removed from all analyses. An example photomicrograph of one side of the CEA bilateral injection site is shown in Figure $1 \mathrm{a}$ and $\mathrm{b}$.

\section{RESULTS}

\section{Effects of DHK on ICSS}

Intra-CEA DHK significantly increased ICSS thresholds in a dose-dependent manner (Figure 1c). At higher doses, intraCEA DHK induced a complete cessation of responding in some rats. In those cases $(n=2 / 8 ; 6.25 \mathrm{nmol}, n=3 / 8$; $9.375 \mathrm{nmol}$, and $n=4 / 8 ; 12.5 \mathrm{nmol})$, the highest stimulation frequency available was used to calculate the threshold. Two-way repeated measures ANOVA revealed significant main effects of dose $(\mathrm{F}(6,42)=9.7 ; p<0.0001)$ and time $(\mathrm{F}(1,7)=41.3 ; p<0.0001)$, and a dose $\times$ time interaction $(\mathrm{F}(6,42)=9.3 ; p<0.0001)$. Follow-up Bonferroni post hoc comparisons indicated that rats treated with high doses of DHK (9.375 and $12.5 \mathrm{nmol}$ ) in the CEA either completely stopped responding or required significantly higher minimum stimulation frequencies to maintain responding in the first 15 min after DHK infusion compared with both vehicletreated and 1.563-nmol-treated rats $(9.375$ and $12.5 \mathrm{nmol}$; $p<0.0001)$. Figure $1 \mathrm{~d}$ shows the effects of intra-CEA DHK on maximum rates of responding (Max Rates). Two-way repeated measures ANOVA revealed statistically significant main effects of dose $(\mathrm{F}(6,42)=17.3 ; p<0.0001)$, time $(\mathrm{F}(1,7)=55.9 ; p<0.0001)$, and a dose $\times$ time interaction $(\mathrm{F}(6,42)=9.9 ; p<0.0001)$. Follow-up Bonferroni post hoc comparisons revealed that rats treated with the higher doses of intra-CEA DHK had significantly blunted Max Rates during the first 15 min after DHK infusion compared with
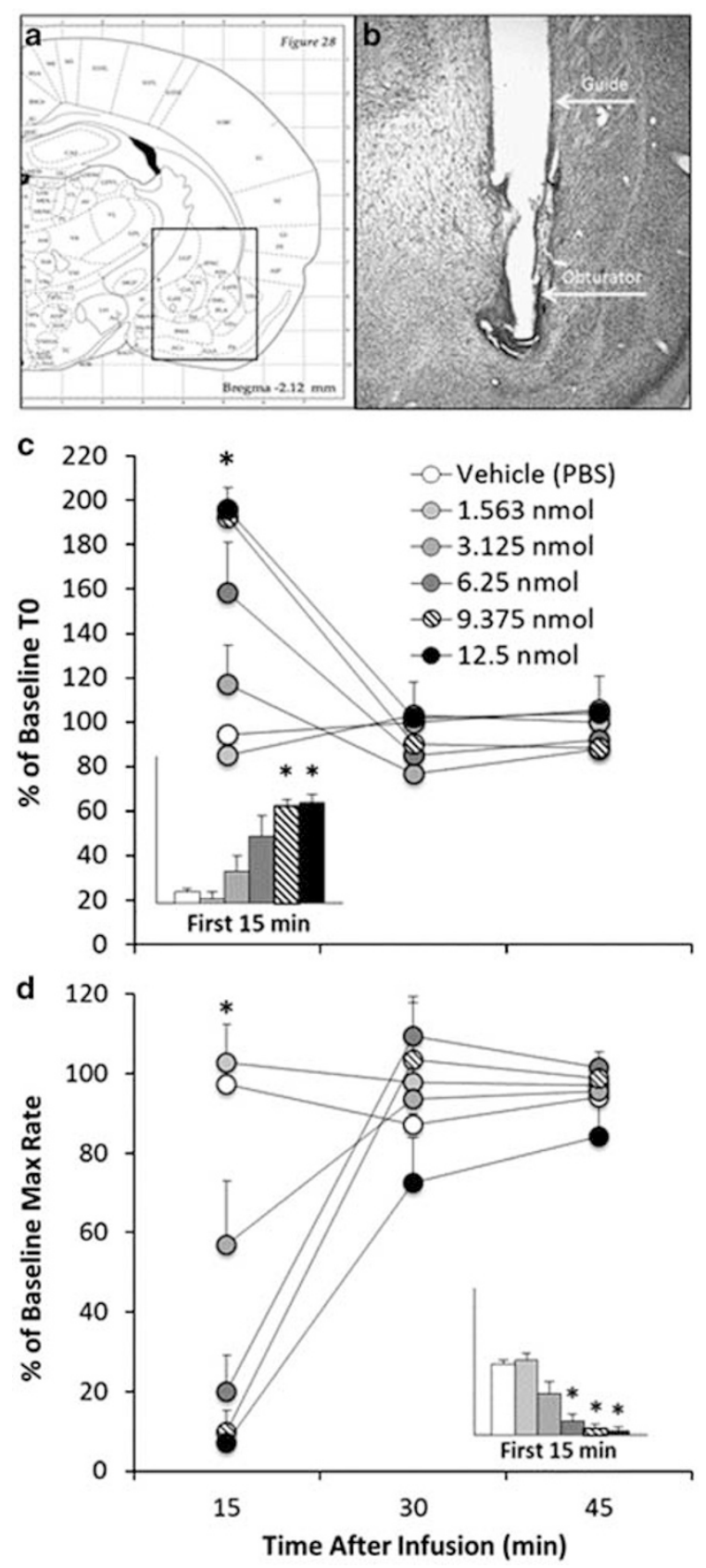

Figure I One side of bilateral intra-CEA-DHK injection sites. (a) Schematic of the CEA indicating location of one side of bilateral cannulae placements (Paxinos and Watson, 2007). Box indicates field of view in panel (b). (b) Figure shows one side of the bilateral cannulae placements of a representative rat indicating guide cannulae and obturator. (c) Effect of intra-CEA DHK $(1.563,3.125,6.25,9.375$, or $12.5 \mathrm{nmol})$ on mean ICSS thresholds (+SEM) over $45 \mathrm{~min}$ after infusion. Inset represents TO (+SEM) within the first $15 \mathrm{~min}$. Follow-up comparisons showed that the effects of DHK were short in duration and dose-dependent. Significant effects were observed during the first $15 \mathrm{~min}$ after DHK infusion and the higher doses of DHK yielded greater thresholds $(9.375$ and $12.5 \mathrm{nmol})$. Time $\times$ Dose interaction: $p<0.0001$. *, Significantly different from the vehicle and $1.563 \mathrm{nmol}$ treatment $(n=8)$. (d) Effect of intra-CEA DHK $(1.563,3.125,6.25,9.375$, or $12.5 \mathrm{nmol})$ on mean ICSS maximum response rate $(+$ SEM) over $45 \mathrm{~min}$ after infusion. Inset represents Max Rates $(+\mathrm{SEM})$ in the first $15 \mathrm{~min}$. Significant effects were observed during the first 15 min after DHK infusion with the higher doses of DHK yielding significant decreases in Max Rates $(6.25,9.375$, and $12.5 \mathrm{nmol})$. Time $\times$ Dose interaction: $p<0.001$. *, Significantly different from the vehicle treatment $(n=8)$. 
vehicle- and 1.563-nmol-treated rats $(6.25,9.375$, and 12.5 ; $p<0.002)$. These blunted Max Rates normalized during the remaining passes. Decreased Max Rates can be the result of decreased hedonic value of stimulation (Do Carmo et al, 2009) or reduced performance ability (Carlezon and Chartoff, 2007). The time-course of these effects are consistent with our previous findings using central (Bechtholt-Gompf et al, 2010) or intra-cortical infusions of DHK (John et al, 2012).

\section{Effects of DHK on EPM Behavior}

As shown in Figure 2, microinfusion of DHK in the CEA induced an anxiogenic response. One-way ANOVA revealed that rats receiving a high dose of intra-CEA DHK $(12.5 \mathrm{nmol})$ spent significantly less time in the open arm of the EPM compared with vehicle-treated rats $(\mathrm{F}(1,14)=$ 6.13; $p<0.05$ ) (Figure 2a). Similarly, intra-CEA DHK also decreased the percent entries the rats made into the open arms of the EPM; however, this trend was not significant $(\mathrm{F}(1,14)=2 ; p=0.18)$ (Figure $2 \mathrm{~b})$, which may be due to the significant decrease in total entries the DHK-treated rats made into both the open or closed arms $(\mathrm{F}(1,14)=6.15$; $p<0.05$ ) (Figure 2c). These data suggest that DHK-treated rats spent less time exploring the open arms of the EPM, an indication of anxiogenesis, as well as less time exploring the maze in general, which could be indicative of more severe anxiogenesis leading to freezing behavior. No significant differences were observed in number of closed arm entries (VEH 8.75 \pm 1.35 ; DHK $5.25 \pm 3.16$ ) distance traveled (cm; VEH 2375.52 \pm 227.55 ; DHK 2020.52 \pm 208.81 ) and velocity (VEH $8.24 \pm 0.79$; DHK $6.83 \pm 0.69$ ) were detected.

\section{Effects of DHK on Fear Conditioning}

To further explore the anxiogenic-like effects associated with intra-CEA DHK that we observed in the EPM, we examined the effects of intra-CEA DHK on acquisition of freezing behavior in a fear-conditioning paradigm. As shown in Figure 3, microinfusion of DHK during conditioning significantly increased freezing behavior compared with vehicle-treated rats when presented with the fearful stimuli during the test $(t(6)=3.4 ; p<0.01)$. However, microinfusion of DHK did not significantly increase freezing behavior in the context alone $(t(6)=0.74 ; p>0.05)$. These results suggest that compared with vehicle-treated rats, rats receiving intra-CEA-DHK during training demonstrate heightened fear when presented with the fearful stimulus $24 \mathrm{~h}$ later.

\section{Effects of DHK on Locomotor Activity}

Figure 4 shows the mean distance traveled and velocity over a 30 min test after a high dose $(12.5 \mathrm{nmol})$ intra-CEA DHK microinfusion. A mixed two-way ANOVA revealed a significant main effect of time $(\mathrm{F}(5,84)=7.4 ; p<0.0001)$, but not significant effects of dose or the interaction of time and dose. Similarly, independent-samples $t$-tests suggested no significant differences between DHK- or vehicle-treated rats on velocity during the first $15 \mathrm{~min}(t(14)=0.107$; $p=0.917$; Figure 4 inset) and the last $15 \mathrm{~min}(t(14)=$ $-0.811 ; p=0.431$; Figure 4 inset) was not significantly different from vehicle-treated rats. These results suggest that decreased Max Rates in the ICSS test and the decreased total arm entries in the EPM were not the result of sedation or impaired locomotion and may be indicative of blunted motivation and/or severe anxiogenesis.

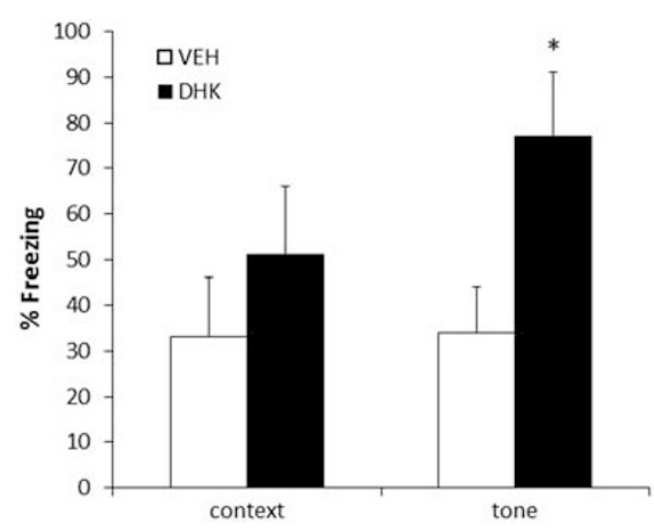

Figure 3 Effect of intra-CEA DHK on fear-conditioning behavior. DHK in the CEA (I $2.5 \mathrm{nmol})$ significantly increased mean (+ SEM) time spent freezing when presented with the fearful stimulus compared with vehicletreated rats. *, Significantly different from vehicle group $p<0.0$ I $(n=8$ per group).
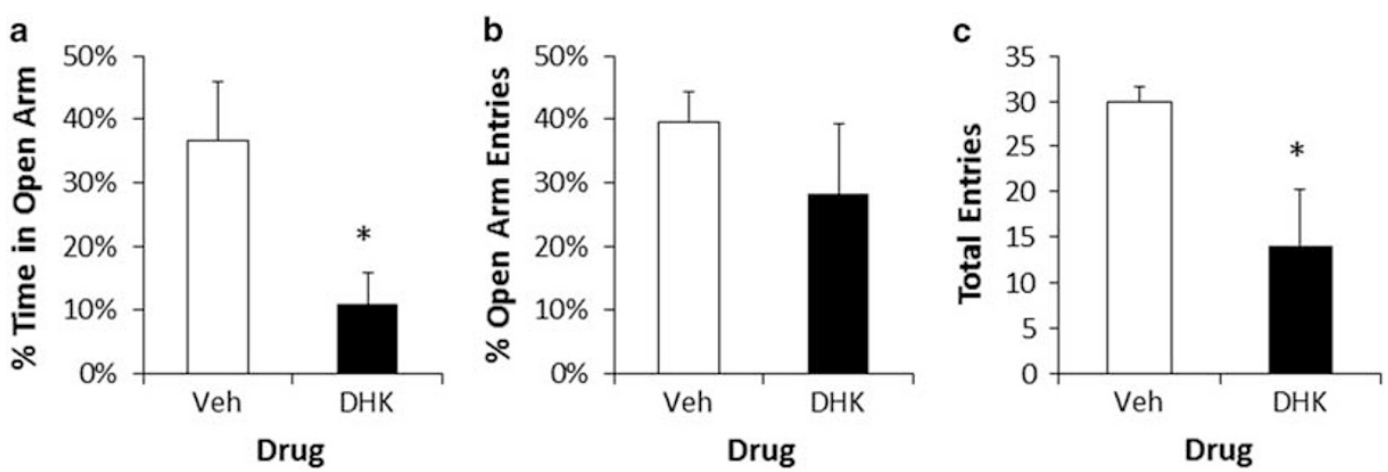

Figure 2 Effect of intra-CEA DHK (I $2.5 \mathrm{nmol})$ on behavior in the elevated plus maze (EPM) over a 5 -min test. (a) DHK in the CEA significantly decreased mean $(+$ SEM) percent time spent in the open arm of the EPM. (b) Intra-CEA DHK did not significantly change mean $(+$ SEM) percent open arm entries. (c) DHK in the CEA significantly decreased total arm entries (closed + open) in the EPM. *, Significantly different from vehicle group $p<0.05$ ( $n=8$ per group). 


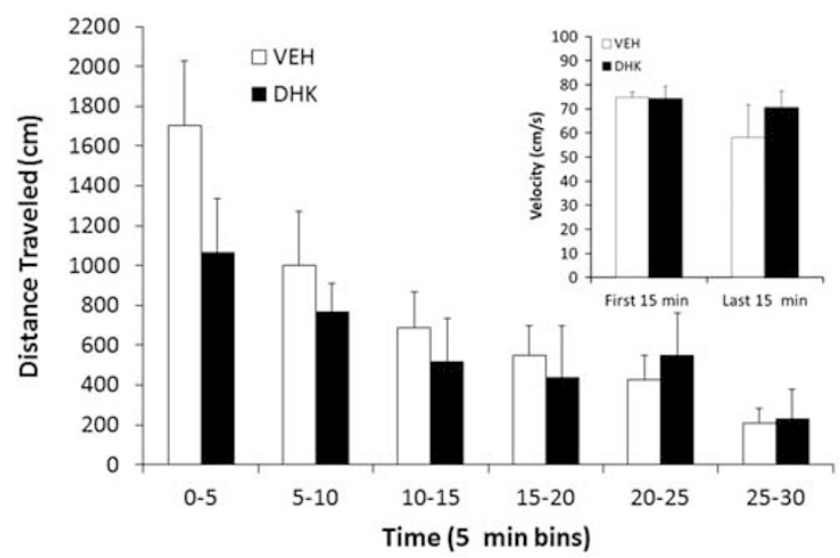

Figure 4 Effect of $12.5 \mathrm{nmol}$ intra-CEA-DHK on locomotor behavior in a 30-min test. DHK in the CEA did not significantly alter mean (+ SEM) distance traveled in the activity chamber. Inset shows that intra-CEA-DHK did not significantly change mean ( + SEM) velocity compared with vehicletreated rats when measured at the first 15 min or the last 15 min $(n=8$ per group).

\section{DISCUSSION}

Here, we report that blocking astrocytic glutamate uptake in the CEA results in both anhedonic- and anxiogenic-like behavior. We have shown that intra-CEA DHK infusion increases reward thresholds in ICSS and increases anxiogenic-like behavior in the EPM and the FPS paradigms. This is the first report to demonstrate that blocking astrocytic glutamate uptake, specifically in the CEA, can induce an animal model of comorbid anxiety and depression, suggesting that glial reductions found in the amygdala of MDD patients may be a pathophysiological trait that contributes to the symptoms of both anxiety and anhedonia.

In the present report, we were able to replicate the anhedonic-like effects that we have previously reported when DHK is infused centrally or into the prefrontal cortex (Bechtholt-Gompf et al, 2010; John et al, 2012) by showing that intra-CEA DHK increases ICSS thresholds (T0) and at the higher doses induced a complete cessation of responding in some rats. This finding is indicative of an anhedonic-like effect and is consistent with previous reports demonstrating that interfering with astrocytic function in specific brain regions can induce signs of depression (Herberg and Rose, 1990; Lee et al, 2007; Banasr and Duman, 2008). We extend the previous literature by showing that blockade of astrocytic glutamate reuptake specifically in the CEA can induce anhedonia. The present findings also suggest that intra-CEA DHK has profound effects on maximum response rates in the ICSS paradigm, which can be indicative of decreased motivation or an anhedonic-like effect (Bechtholt-Gompf et al, 2010), as either decreasing the intensity of the stimulation or increasing the response requirement decreases maximum response rates (Do Carmo et al, 2009). Previous reports have shown that increased glutamate levels in the amygdala can induce other signs of depression such as social avoidance and disrupted circadian rhythms in rats
(Lee et al, 2007). These findings add to growing evidence that increased glutamate levels in the amygdala may induce a number of the symptoms of depression.

Another major finding in the current work was the ability of disrupted astrocytic glutamatergic transmission to induce profound effects on anxiety in rats. Specifically, intra-CEA DHK decreased percent time spent in the open arm of the EPM, an anxiogenic-like effect. Intra-CEA DHK did not significantly affect percent open arm entries, but this lack of effect may have been due to an overall significant decrease in the number of entries into either arm of the EPM. As increases in glutamate can have effects on motor activity, we evaluated gross motor behavior using a locomotor assay. As shown in Figure 4, $12.5 \mathrm{nmol}$ intraCEA DHK had no significant effects on overall distance travelled or velocity during a 30-min test. These results help interpret both our ICSS and EPM data, suggesting that in the ICSS paradigm, decreases in maximum response rates were not a result of impaired motor behavior. Injection of the stress hormone, corticotrophin releasing factor, has been reported to increase reward thresholds in ICSS (Macey et al, 2000), suggesting that anxiety alone may induce an anhedonic phenotype. Taken together, these data suggest that the decrease in the total number of entries we observed in the EPM as well as the increased reward threshold and decreased Max Rates observed in ICSS were not artifacts of impaired locomotion and likely due to severe anxiogenesis and anxiety-induced anhedonia. The decrease in percent time spent in the open arms coupled with a significant reduction in total arm entries suggests that the rats displayed an avoidance of the fear-provoking arms as well as decreased overall exploration of the maze and general activity. Immobility and freezing behavior are common responses to induction of unconditioned fear in rodents (for review see Misslin, 2003), and the present data suggest intra-CEA DHK may induce severe anxiety as measured by decreased open arm time and increased immobility in the EPM.

To further explore and better understand the anxiogenic effects of intra-CEA DHK that we observed in the EPM, we used the fear-conditioning paradigm as another measure of fear and anxiety. Infusion of DHK in the CEA significantly increased freezing behavior when the animals were tested in a previously paired fearful context, a result that suggests intra-CEA DHK potentiates the fear response when paired with a stressful environment. Increased amygdalar activity can induce higher levels of fear that may recruit different modes of defensive responding such as increased freezing behavior (for review see Walker et al, 1997; Davis, 2006). These data are in agreement with previous reports that have shown negative or blunted startle amplitudes owing to higher doses of anxiogenic compounds in a fear-potentiated startle paradigm (Knoll et al, 2011; Reimer et al, 2012). Furthermore, these data are consistent with our EPM data showing increased immobility (freezing behavior) after intra-CEA DHK. Increases in glutamate in specific brain regions have been shown to disrupt fear conditioning, and it has been suggested that the dense glutamatergic connections between the CEA, bed nucleus of the stria terminalis, and dorsal periaqueductal gray control the freezing response induced by increased anxiety (for review see Walker et al, 1997; Davis, 2006). 
The exact mechanisms through which fewer glia and resultant increases in glutamate could contribute to comorbid depression and anxiety are unknown. However, some data suggest that a lack of astrocytes can lead to glutamate dysregulation, and consequent elevated glutamate levels, which may play a role in the expression of anxiety and depression symptoms, including anhedonia. Deep brain stimulation data in patients with treatment-resistant depression suggest that there is a baseline increase in activation of area Cg25 that is normalized by deep brain stimulation treatment (Mayberg et al, 2005). And, some data suggest that there is an increase in activity of the amygdala that is positively correlated with MDD symptom severity (Abercrombie et al, 1998). These two sets of findings are likely related because the amygdala has dense connections and close proximity to area Cg25 (Ongur and Price, 2000). Taken together, these data suggest that increased activity of these cortical regions could lead to heightened symptoms of depression. With such high levels of comorbidity between GAD and MDD, some have tested the possibility that GAD is a prodromal marker of depression (Kessler et al, 2008; Sunderland et al, 2010) and suggested that the underlying abnormalities that contribute to depression also contribute to depressioninduced anxiety. Similarly, it has been reported that rats susceptible to depression show increased glial proliferation in the amygdala after electroconvulsive treatment, suggesting a direct link between effective treatments and proliferation of glia in the amygdala (Wennstrom et al, 2004).

In the present work, we have not definitively shown that intra-CEA DHK infusion increases glutamate levels in the CEA. However, previous work has shown that infusion of DHK directly into a specific brain region increases extracellular glutamate levels in the same region (eg, Fallgren and Paulsen, 1996) and that other mood-related effects of DHK infused into the amygdala are blocked by AP5, an N-methyl-D-aspartate receptor antagonist (Lee et al, 2007). It has also been reported that site-specific DHK infusion can have effects other than increasing glutamate. For example, infusions of high doses of DHK into the hippocampus can elevate taurine levels (Lehmann and Hamberger, 1983) and taurine supplementation, alone, can increase anxiety (El Idrissi et al, 2009). Interestingly, infusion of DHK directly in the amygdala also increases lactate, which is indicative of increased neuronal activity and energy use (Uehara et al, 2007). Thus, we are unable to rule out other potential effects of DHK in inducing the observed effects. The likelihood of some of these effects are, however, diminished by the low doses employed here, which are 10-100 fold lower than those known to increase taurine levels and similar to those that induce lactate. Taken together, it seems likely that DHK infusions increase activation of the CEA-an effect that is consistent with reports in depressed humans wherein over-activation (Ketter et al, 2001) and glial deficits (Bowley et al, 2002) in the amygdala are observed.

We have shown that blocking astrocytic glutamate uptake in the CEA can induce both anhedonia and anxiety-two common features of depression. This dysfunction was achieved by direct infusion of the GLT-1 inhibitor DHK into the CEA, which pharmacologically mimics one aspect of the loss of glia that is observed in patients with depression. These data suggest that the lack of amygdalar astrocytes observed in MDD patients may have a causal role in producing the pervasive anxiety that many individuals with depression exhibit by demonstrating that alterations in astrocytic function could contribute to both anxiogenic and anhedonic symptoms. The present report suggests that restoration or enhancement of astrocytic function could be an effective and novel treatment capable of targeting the anxiety that is so often comorbid with depression.

\section{FUNDING AND DISCLOSURE}

The authors have no conflicts of interest relating to this report and Dr Bechtholt, Catherine John, and Elizabeth Sypek have no other potential conflicts to report. Dr Carlezon has a US patent covering the use of kappa antagonists in the treatment of depression (Assignee: McLean Hospital) and is a member of a collaborative group, including Dr Cohen, that has submitted a patent application covering the synthesis and use of salvinorin derivatives (Assignees: McLean Hospital and Temple University). In the last three years, Dr Carlezon has received compensation for professional services from The American College of Neuropsychopharmacology and Myneurolab. com. Dr Öngür is a Principal Investigator on a research contract with Rules Based Medicine Inc., has served on an advisory board for Lilly, and has received income from Archives of General Psychiatry for services in 2012. Dr Cohen has three additional pending patents on Pyrimidines to treat bipolar disorders, Kappa agonists in bipolar mania, and Mitochondrial replacement therapy and a book on bipolar disorder that has been published by Jossey-Bass/Wiley.

\section{ACKNOWLEDGMENTS}

Funding for this work was provided by the Jerome Lyle Rappaport Charitable Foundation, the National Alliance for Research on Schizophrenia and Depression \& the National Institute of Mental Health MH087695, AJB; the Shervert Frazier Research Institute, BMC \& DO; Englehard Foundation, BMC; MH063266, WAC. We would like to thank Dr Eddie Meloni for his significant contributions to the fearconditioning experiments in preparing this manuscript.

\section{REFERENCES}

Abercrombie HC, Schaefer SM, Larson CL, Oakes TR, Lindgren KA, Holden JE et al (1998). Metabolic rate in the right amygdala predicts negative affect in depressed patients. Neuroreport 9: 3301-3307.

Altshuler LL, Abulseoud OA, Foland-Ross L, Bartzokis G, Chang S, Mintz J et al (2010). Amygdala astrocyte reduction in subjects with major depressive disorder but not bipolar disorder. Bipolar Disord 12: 541-549.

Anderson CM, Swanson RA (2000). Astrocyte glutamate transport: review of properties, regulation, and physiological functions. Glia 32: 1-14.

Arriza JL, Fairman WA, Wadiche JI, Murdoch GH, Kavanaugh MP, Amara SG (1994). Functional comparisons of three glutamate transporter subtypes cloned from human motor cortex. J Neurosci 14: 5559-5569. 
Banasr M, Duman RS (2008). Glial loss in the prefrontal cortex is sufficient to induce depressive-like behaviors. Biol Psychiatry 64: 863-870.

Bechtholt-Gompf AJ, Walther HV, Adams MA, Carlezon WA Jr, Ongur D, Cohen BM (2010). Blockade of astrocytic glutamate uptake in rats induces signs of anhedonia and impaired spatial memory. Neuropsychopharmacology 35: 2049-2059.

Blumberg HP, Fredericks C, Wang F, Kalmar JH, Spencer L, Papademetris X et al (2005). Preliminary evidence for persistent abnormalities in amygdala volumes in adolescents and young adults with bipolar disorder. Bipolar Disord 7: 570-576.

Blumberg HP, Kaufman J, Martin A, Whiteman R, Zhang JH, Gore JC et al (2003). Amygdala and hippocampal volumes in adolescents and adults with bipolar disorder. Arch Gen Psychiatry 60: 1201-1208.

Bowley MP, Drevets WC, Ongur D, Price JL (2002). Low glial numbers in the amygdala in major depressive disorder. Biol Psychiatry 52: 404-412.

Brawman-Mintzer O, Lydiard RB, Emmanuel N, Payeur R, Johnson M, Roberts J et al (1993). Psychiatric comorbidity in patients with generalized anxiety disorder. Am J Psychiatry 150: 1216-1218.

Brown TA, Marten PA, Barlow DH (1995). Discriminant validity of the symptoms constituting the DSM-III-R and DSM-IV associated symptom criterion of generalized anxiety disorder. J Anxiety Disord 9: 317-328.

Carlezon WA Jr, Chartoff EH (2007). Intracranial self-stimulation (ICSS) in rodents to study the neurobiology of motivation. Nat Protoc 2: 2987-2995.

Carmichael ST, Price JL (1995). Limbic connections of the orbital and medial prefrontal cortex in macaque monkeys. J Comp Neurol 363: 615-641.

Chang K, Karchemskiy A, Barnea-Goraly N, Garrett A, Simeonova DI, Reiss A (2005). Reduced amygdalar gray matter volume in familial pediatric bipolar disorder. J Am Acad Child Adolesc Psychiatry 44: 565-573.

Chaudhry FA, Lehre KP, van Lookeren Campagne M, Ottersen OP, Danbolt NC, Storm-Mathisen J (1995). Glutamate transporters in glial plasma membranes: highly differentiated localizations revealed by quantitative ultrastructural immunocytochemistry. Neuron 15: 711-720.

Choudary PV, Molnar M, Evans SJ, Tomita H, Li JZ, Vawter MP et al (2005). Altered cortical glutamatergic and GABAergic signal transmission with glial involvement in depression. Proc Natl Acad Sci USA 102: 15653-15658.

Davis M (2006). Neural systems involved in fear and anxiety measured with fear-potentiated startle. Am Psychologist 61: 741-756.

Do Carmo GP, Folk JE, Rice KC, Chartoff E, Carlezon WA Jr, Negus SS (2009). The selective non-peptidic delta opioid agonist SNC80 does not facilitate intracranial self-stimulation in rats. Eur J Pharmacol 604: 58-65.

Drevets WC (2000). Functional anatomical abnormalities in limbic and prefrontal cortical structures in major depression. Prog Brain Res 126: 413-431.

El Idrissi A, Boukarrou L, Heany W, Malliaros G, Sangdee C, Neuwirth L (2009). Effects of taurine on anxiety-like and locomotor behavior in mice. Adv Exp Med Biol 643: 207-215.

Fallgren AB, Paulsen RE (1996). A microdialysis study in rat brain of dihydrokainate, a glutamate uptake inhibitor. Neurochem Res 21: $19-25$.

Gadermann AM, Alonso J, Vilagut G, Zaslavsky AM, Kessler RC (2012). Comorbidity and disease burden in the National Comorbidity Survey Replication (NCS-R). Depress Anxiety 29: 797-806.

Gosselin RD, Gibney S, O’Malley D, Dinan TG, Cryan JF (2009). Region specific decrease in glial fibrillary acidic protein immunoreactivity in the brain of a rat model of depression. Neuroscience 159: 915-925.

Hashimoto K, Sawa A, Iyo M (2007). Increased levels of glutamate in brains from patients with mood disorders. Biol Psychiatry 62: $1310-1316$

Haugeto O, Ullensvang K, Levy LM, Chaudhry FA, Honore T, Nielsen $M$ et al (1996). Brain glutamate transporter proteins form homomultimers. J Biol Chem 271: 27715-27722.

Herberg LJ, Rose IC (1990). Excitatory amino acid pathways in brain-stimulation reward. Behav Brain Res 39: 230-239.

Jardine R, Martin NG, Henderson AS (1984). Genetic covariation between neuroticism and the symptoms of anxiety and depression. Genet Epidemiol 1: 89-107.

John CS, Smith KL, Van't Veer A, Gompf HS, Carlezon WA Jr, Cohen BM et al (2012). Blockade of astrocytic glutamate uptake in the prefrontal cortex induces anhedonia. Neuropsychopharmacology 37: 2467-2475.

Johnston GA, Kennedy SM, Twitchin B (1979). Action of the neurotoxin kainic acid on high affinity uptake of L-glutamic acid in rat brain slices. J Neurochem 32: 121-127.

Kessler RC, DuPont RL, Berglund P, Wittchen HU (1999). Impairment in pure and comorbid generalized anxiety disorder and major depression at 12 months in two national surveys. Am J Psychiatry 156: 1915-1923.

Kessler RC, Gruber M, Hettema JM, Hwang I, Sampson N, Yonkers KA (2008). Co-morbid major depression and generalized anxiety disorders in the National Comorbidity Survey follow-up. Psychol Med 38: 365-374.

Ketter TA, Kimbrell TA, George MS, Dunn RT, Speer AM, Benson BE et al (2001). Effects of mood and subtype on cerebral glucose metabolism in treatment-resistant bipolar disorder. Biol Psychiatry 49: 97-109.

King-Kallimanis B, Gum AM, Kohn R (2009). Comorbidity of depressive and anxiety disorders for older Americans in the national comorbidity survey-replication. Am J Geriatr Psychiatry 17: 782-792.

Knoll AT, Muschamp JW, Sillivan SE, Ferguson D, Dietz DM, Meloni EG et al (2011). Kappa opioid receptor signaling in the basolateral amygdala regulates conditioned fear and anxiety in rats. Biol Psychiatry 70: 425-433.

Lee Y, Gaskins D, Anand A, Shekhar A (2007). Glia mechanisms in mood regulation: a novel model of mood disorders. Psychopharmacology 191: 55-65.

Lehre KP, Danbolt NC (1998). The number of glutamate transporter subtype molecules at glutamatergic synapses: chemical and stereological quantification in young adult rat brain. J Neurosci 18: 8751-8757.

Lehre KP, Levy LM, Ottersen OP, Storm-Mathisen J, Danbolt NC (1995). Differential expression of two glial glutamate transporters in the rat brain: quantitative and immunocytochemical observations. J Neurosci 15: 1835-1853.

Lehmann A, Hamberger A (1983). Dihydrokainic acid affects extracellular taurine and phosphoethanolamine levels in the hippocampus. Neurosci Lett 38: 67-72.

Macey DJ, Koob GF, Markou A (2000). CRF and urocortin decreased brain stimulation reward in the rat: reversal by a CRF receptor antagonist. Brain Res 866: 82-91.

Mayberg HS, Lozano AM, Voon V, McNeely HE, Seminowicz D, Hamani C et al (2005). Deep brain stimulation for treatmentresistant depression. Neuron 45: 651-660.

Mervaala E, Fohr J, Kononen M, Valkonen-Korhonen M, Vainio P, Partanen K et al (2000). Quantitative MRI of the hippocampus and amygdala in severe depression. Psychol Med 30: 117-125.

Miliaressis E, Rompre PP, Laviolette P, Philippe L, Coulombe D (1986). The curve-shift paradigm in self-stimulation. Physiol Behav 37: 85-91.

Mineka S, Watson D, Clark LA (1998). Comorbidity of anxiety and unipolar mood disorders. Annu Rev Psychol 49: 377-412. 
Misslin R (2003). The defense system of fear: behavior and neurocircuitry. Neurophysiol 33: 55-66.

Montgomery KC (1955). The relation between fear induced by novel stimulation and exploratory behavior. J Comp Physiol Psychol 48: 254-260.

Newman MG, Przeworski A, Fisher AJ, Borkovec TD (2010). Diagnostic comorbidity in adults with generalized anxiety disorder: impact of comorbidity on psychotherapy outcome and impact of psychotherapy on comorbid diagnoses. Behav Ther 41: 59-72.

Ongur D, Price JL (2000). The organization of networks within the orbital and medial prefrontal cortex of rats, monkeys and humans. Cereb Cortex 10: 206-219.

Paxinos G, Watson C. (2007). The rat brain in stereotaxic coordinates. Academic Press: New York.

Reimer AE, de Oliveira AR, Brandao ML (2012). Glutamatergic mechanisms of the dorsal periaqueductal gray matter modulate the expression of conditioned freezing and fear-potentiated startle. Neuroscience 219: 72-81.

Robinson MB, Hunter-Ensor M, Sinor J (1991). Pharmacologically distinct sodium-dependent L-[3H]glutamate transport processes in rat brain. Brain Res 544: 196-202.

Rosso IM, Killgore WD, Cintron CM, Gruber SA, Tohen M, Yurgelun-Todd DA (2007). Reduced amygdala volumes in first-episode bipolar disorder and correlation with cerebral white matter. Biol Psychiatry 61: 743-749.

Sanacora G, Gueorguieva R, Epperson CN, Wu YT, Appel M, Rothman DL et al (2004). Subtype-specific alterations of gamma- aminobutyric acid and glutamate in patients with major depression. Arch Gen Psychiatry 61: 705-713.

Sheline YI, Gado MH, Price JL (1998). Amygdala core nuclei volumes are decreased in recurrent major depression. Neuroreport 9: 2023-2028.

Sunderland M, Mewton L, Slade T, Baillie AJ (2010). Investigating differential symptom profiles in major depressive episode with and without generalized anxiety disorder: true co-morbidity or symptom similarity? Psychol Med 40: 1113-1123.

Uehara T, Sumiyoshi T, Itoh H, Kurachi M (2007). Role of glutamate transporters in the modulation of stress-induced lactate metabolism in the rat brain. Psychopharmacology 195: 297-302.

Walker DL, Cassella JV, Lee Y, De Lima TC, Davis M (1997). Opposing roles of the amygdala and dorsolateral periaqueductal gray in fear-potentiated startle. Neurosci Biobeh Rev 21: 743-753.

Walf AA, Frye CA (2007). The use of elevated plus maze as an assay of anxiety-related behavior in rodents. Nat Protoc 2: 322-328.

Wennstrom M, Hellsten J, Tingstrom A (2004). Electroconvulsive seizures induce proliferation of NG2-expressing glial cells in adult rat amygdala. Biol Psychiatry 55: 464-471.

Zbozinek TD, Rose RD, Wolitzky-Taylor KB, Sherbourne C, Sullivan G, Stein MB et al (2012). Diagnostic overlap of generalized anxiety disorder and major depressive disorder in a primary care sample. Depress Anxiety 29: 1065-1071.

Zimmerman M, Chelminski I (2003). Generalized anxiety disorder in patients with major depression: is DSM-IV's hierarchy correct? Am J Psychiatry 160: 504-512. 